\title{
Identification of novel stress-responsive biomarkers from gene expression datasets in tomato roots
}

Almudena Ferrández-Ayela ${ }^{\mathrm{A}}$, Ana Belén Sánchez-García ${ }^{\mathrm{A}}$, Cristina Martínez-Andújar ${ }^{\mathrm{B}}$, Zoltan Kevei $^{\mathrm{C}}$, Miriam L. Gifford ${ }^{\mathrm{D}}$, Andrew A. J. Thompson ${ }^{\mathrm{C}}$, Francisco Pérez-Alfocea ${ }^{\mathrm{B}}$ and José Manuel Pérez-Pérez $^{\mathrm{A}, \mathrm{E}}$

A Instituto de Bioingeniería, Universidad Miguel Hernández, 03202 Elche, Spain.

${ }^{\mathrm{B}}$ Departamento de Nutrición Vegetal. CEBAS-CSIC, Campus de Espinardo, 30100 Murcia, Spain. ${ }^{\mathrm{C}}$ Cranfield Soil and AgriFood Institute, School of Energy, Environment and Agrifood, Cranfield University, Cranfield, Bedfordshire, MK43 OAL, UK.

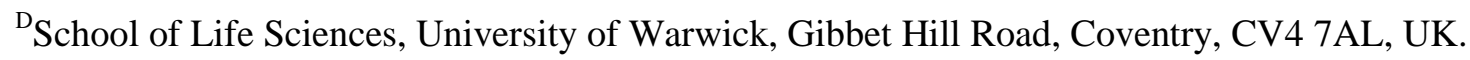

${ }^{\mathrm{E}}$ Corresponding author. Email: jmperez@umh.es

Abiotic stresses such as heat, drought or salinity have been widely studied individually. Nevertheless, in the nature and in the field, plants and crops are commonly exposed to a different combination of stresses, which often result in a synergistic response mediated by the activation of several molecular pathways that cannot be inferred from the response to each individual stress. By screening microarray data obtained from different plant species and under different stresses, we identified several conserved stress-responsive genes whose expression was differentially regulated in tomato (Solanum lycopersicum L.) roots in response to one or several stresses. We validated 10 of these genes as reliable biomarkers whose expression levels are related to different signalling pathways involved in adaptive stress responses. In addition, the genes identified in this work could be used as general salt-stress biomarkers to rapidly evaluate the response of salt-tolerant cultivars and wild species for which sufficient genetic information is not yet available.

Additional keywords: abiotic stress, gene expression profiling, stress biomarkers, salt-stress responsive genes.

A. Ferrández-Ayela et al.

Stress-responsive biomarkers in tomato roots

In nature and in the field, plants and crops are commonly exposed to different stresses. By screening public gene expression data, we identified several conserved stress-responsive genes in tomato roots that could be used as biomarkers to rapidly evaluate the response of salt-tolerant cultivars and wild species for which sufficient genetic information is not yet available.

\section{Introduction}

Several lines of evidence indicate that the increase in atmospheric $\mathrm{CO}_{2}$ level is driving global climate changes that will likely result in a higher frequency of heatwaves, episodes of prolonged drought and flooding (Bates et al. 2008). Since plants are not able to physically escape these stresses, adverse environmental conditions represent a serious challenge for agricultural production (Mittler and 
Blumwald 2010). This fact, together with the increasing demand for food caused by a rising worldwide population make necessary an increasing understanding of how plants and crops respond to a combination of stresses. Abiotic stresses such as heat, drought or salinity have been widely studied individually, but in ecosystems and in the field, plants and crops are commonly exposed to a combination of different stresses such as heat and drought, or salinity and drought, for example (Mittler 2006). Further, the combination of different abiotic stresses often results in a synergistic response mediated by the activation of several molecular pathways that cannot be inferred from the response to each individual stress alone (Pnueli et al. 2002; Rizhsky et al. 2002, 2004; Mittler 2006). In turn, the adaptive responses to different abiotic stresses also imply the activation of specific bioticresponse pathways that could positively or negatively affect plant survival. For instance, it has been reported that Arabidopsis plants showed an enhanced susceptibility to Pseudomonas syringae and Hyaloperonospera arabidopsidis in drought conditions (Mohr and Cahill 2003). Furthermore, the increase of tolerance to drought, salt and osmotic stress in tomato and barley fosters the resistance to different pathogens (Wiese et al. 2004; Achuo et al. 2006).

These and other results indicate that the response to diverse stresses involves a complex and coordinated crosstalk between different signalling pathways (Zhu 2002). The level at which these pathways interact includes different signalling complexes; calcium and/or reactive oxygen species (ROS) signalling; mitogen-activated protein kinase (MAPK) cascades; and stress hormones such as abscisic acid (ABA), jasmonic acid (JA), salicylic acid (SA) and ethylene (Bowler and Fluhr 2000; Cardinale et al. 2002; Zhu 2002; Xiong and Yang 2003; Mittler 2006). Among stress hormones, ABA is one of the most important components of the abiotic-stress transduction pathways. However, diverse studies have determined the existence of a complex interplay between ABA, SA, JA and ethylene in response to different abiotic stresses (Grant and Jones 2009; Pieterse et al. 2009).

The existence of multiple transcriptome datasets for different abiotic stresses and in different species provides the opportunity to identify and characterise key conserved genes downstream of shared stress responses. Some of these genes might be eventually used as biomarkers for the evaluation of stress responses in crop breeding programs; they could also expand our knowledge about the genetic mechanisms underlying the responses to combined stresses in non-model crops. In tomato (Solanum lycopersicum L.), for instance, salt-specific responsive genes have been identified using a combination of suppression subtractive hybridisation and microarray analyses (Ouyang et al. 2007; Sun et al. 2010).

Because of its agronomic interest, we are using tomato as a crop model system. Given that a large number of microarray datasets are publicly available and with the aim to contribute to a better knowledge of the complex molecular mechanisms of plant abiotic responses in this species, we performed a data mining approach to identify conserved salt stress-responsive genes and to search for tomato genes whose expression in roots was significantly affected by more than one abiotic stress 
conditions. Next, we experimentally validated whether the expression of some of the genes selected was affected by several stresses, in order to be used as biomarkers for the quantification of molecular adaptive responses to single or combined abiotic stresses in this and other species.

\section{Materials and methods}

\section{Data mining for the identification of putative stress-responsive genes}

To find genes whose expression was altered in response to salt stress, we searched available literature for comparative microarray analyses between salt-tolerant and salt-susceptible cultivars in different plant species (Rensink et al. 2005; Cotsaftis et al. 2011; Fujita et al. 2011; Iyer-Pascuzzi et al. 2011; Yao et al. 2011; Huang et al. 2012). We selected for further analysis some of the functionally validated genes whose expression was significantly altered upon salt stress (see Table S1, available as Supplementary Material to this paper). To identify putative tomato (Solanum lycopersicum L.) homologues of the genes selected, their protein sequences were searched for homology against all annotated tomato proteins (ITAG release 2.30) using the BLAST tool in the Sol Genomics Network database (https://solgenomics.net/). The expression in roots of these tomato orthologues upon salt and drought stress was confirmed by the analysis of available microarray data (GSE16401; (Sun et al. 2010) using the Anatomy Tool in Genevestigator 4.

In addition, four tomato microarray datasets from experiments related to abiotic stresses: salinity (GSE16401; (Sun et al. 2010), nitrogen availability (GSE21020; (Ruzicka et al. 2010), and drought and heat stresses (GSE22304), were screened for genes with differential expression by using the GEO2R tool. Additional information about the datasets considered could be found at Gene Expression Omnibus (Barrett et al. 2013); http://www.ncbi.nlm.nih.gov/geo/) The Affymetrix microarrays used in these studies contained probes for 7405 tomato unigenes, which only represent $39 \%$ of the 18051 genes identified in the tomato genome (The Tomato Genome Consortium 2012). Differentially expressed genes were defined by probes with a Benjamini-Hochberg adjusted $P \leq 0.05$ (Benjamini and Hochberg 1995) and a fold change $>1.75$. Only unambiguous probes hybridising with unique tomato genes were kept for further analyses. Relative expression data from the selected genes was processed using the pheatmap package of R Development Core Team (R Foundation for Statistical Computing, Vienna, Austria); http://www.r-project.org/). Euclidean distance matrixes between genes (rows) and between fold-change expression in different experiments (columns) were calculated to build the dendrograms. Gene ontology (GO) terms analysis in the set of differentially expressed genes and pathways that were affected by the stress-treatment was performed using the Plant MetGenMAP (Joung et al. 2009) and statistically significantly-enriched GO categories assigned based on a Benjamini-Hochberg adjusted $P \leq 0.05$ 


\section{Plant material and growth conditions}

Seeds of Ailsa Craig (AC), a wild-type tomato cultivar, and flacca (flc), an ABA deficient mutant affected in a molybdenum cofactor sulfurase required for ABA biosynthesis (Sagi et al. 2002) were kindly provided by Ian Dodd (University of Lancaster, UK). Seeds were washed in 70\% (v/v) ethanol for $30 \mathrm{~s}$, surface-sterilised in $2 \%(\mathrm{w} / \mathrm{v})$ sodium hypochlorite for $12 \mathrm{~min}$, and rinsed thoroughly with sterile distilled water (five times). On the first experiment (early response), 3-5 seeds of each genotype were sown on a square Petri dish containing $100 \mathrm{~mL}$ of half-Murashige and Skoog (Murashige and Skoog 1962) basal salt medium (Duchefa Biochemie, BH Haarlen, The Netherlands), $20 \mathrm{~g}^{-1}$ sucrose (Duchefa Biochemie), $8 \mathrm{~g} \mathrm{l}^{-1}$ plant agar (Duchefa Biochemie), and $0.5 \mathrm{~g}^{-1} 2$-( $\mathrm{N}$ morpholino) ethanesulfonic acid (MES; Duchefa Biochemie), pH 5.8. Six plates were sown per genotype. After a 4 day stratification period at $4^{\circ} \mathrm{C}$ in the dark, seeds were left to germinate in nearvertical positions in a growth chamber at $24 \pm 1^{\circ} \mathrm{C}, 60 \% \mathrm{RH}$ and a $16 \mathrm{~h}$ day (PPFD at $150 \mu \mathrm{mol} \mathrm{m} \mathrm{s}^{-2}$ ${ }^{1}$ ) and $8 \mathrm{~h}$ night cycle. Seedlings of both genotypes were grown as described until the first lateral roots emerged (at $\sim 7$ days), when plants were transferred to new Petri dishes supplemented with $75 \mathrm{mM}$ $\mathrm{NaCl}, 1 \mu \mathrm{M}$ 2-cis, 4-trans-abscisic acid (ABA; Duchefa Biochemie) or mock (DMSO) treatment. Three randomly collected roots from each plate were harvested at $6 \mathrm{~h}$ after the transfer to the supplemented media, frozen in liquid nitrogen and stored at $-65^{\circ} \mathrm{C}$ until analysis. Three biological replicates were collected per each genotype, treatment and time-point.

For the long-term experiments on salt, seeds of AC were germinated in vermiculite at $26-28^{\circ} \mathrm{C}, 80$ $90 \% \mathrm{RH}$ and darkness. Following germination, growth chamber conditions were set at $16 \mathrm{~h}$ day (PPFD at $245 \mu$ moles $\mathrm{m}^{-2} \mathrm{~s}^{-1}$ ) and $8 \mathrm{~h}$ night cycle and 40-60\% RH. The air temperature ranged from 25 to $28^{\circ} \mathrm{C}$ during the day and 17 to $18^{\circ} \mathrm{C}$ at night. Fourty days after sowing, the plants were transferred to a hydroponic culture by using 20 L plastic trays containing half-strength Hoagland's nutrient solution. After 1 week of acclimatisation, plants were exposed to 0 (control) or $100 \mathrm{mM} \mathrm{NaCl}$ added to the nutrient solution for 11 days. The roots of each plant were harvested and immediately frozen with liquid nitrogen and stored at $-80^{\circ} \mathrm{C}$ until analysis. Three biological replicates per each treatment were chosen for RNA isolation and subsequent real-time quantitative PCR quantitative (RTqPCR) analysis.

For microarray experiments, a recombinant inbred line known as A4 from the cross $S$. lycopersicum var. cerasiforme E9 $\times$ Solanum pimpinellifolium L. line L5 (Monforte et al. 1997) was used. This RIL was a control line in a study to fine map a quantitative trait loci (QTL) that affected fruit weight under salinity (AAJ Thompson, Z Kevei, unpubl. data). The rootstock of A4 was grafted to scions of $S$. lycopersicum cv. Boludo in $20 \mathrm{~mL}$ modules of peat-based compost, and then 3-week-old grafted plants were transplanted into pots containing medium grade perlite (Sinclair, LBS Horticulture, Colne, Lancashire, UK). For the control treatment, plants were irrigated daily to pot capacity with Hoagland solution containing $1 \mathrm{mM} \mathrm{H}_{3} \mathrm{PO}_{4}$ (control treatment with excess phosphorus). For the drought and low 
phosphorus multi-stress treatment, plants were initially irrigated to pot capacity with Hoagland solution containing no added $\mathrm{H}_{3} \mathrm{PO}_{4}$ for a period of 19 days after transplanting (to deplete phosphorus in the transplanted peat block); then, for the subsequent 10 days, the pots were irrigated to $70 \%$ of pot capacity with Hoagland solution containing a low $\mathrm{H}_{3} \mathrm{PO}_{4}$ concentration $(10 \mu \mathrm{M})$ to provide the drought and low phosphorus treatment. For microarray analysis $\sim 0.5 \mathrm{~g}$ of root tissue was sampled midway between the base of the plant and the base of the pot by removing a handful of root/perlite material during the time period 1000 and 1100 hours Greenwich mean time (GMT) (dawn was at 0548 hours). Perlite was washed from the roots with tap water (sampling process taking $\sim 90 \mathrm{~s}$ ) and then the roots were frozen in liquid nitrogen.

\section{RNA isolation and first-strand cDNA synthesis for real-time quantitative PCR assays}

Total RNA from frozen tomato roots $(\sim 150 \mathrm{mg})$ was extracted using Tri-Reagent (Sigma-Aldrich, St Louis, MO, USA). Contaminating genomic DNA was removed by $20 \mathrm{~min}$ incubation at $37^{\circ} \mathrm{C}$ with 4 units of DNase I (Thermo Fisher Scientific, Waltham, MA, USA). After DNase I inactivation at $70^{\circ} \mathrm{C}$ for $15 \mathrm{~min}$, RNA was ethanol-precipitated and resuspended in $30 \mu \mathrm{L}$ of diethylpyrocarbonate (DEPC)-treated water. The first strand cDNA was synthesised with $1 \mu \mathrm{g}$ of purified RNA using the iScript Reverse Transcription Supermix for RT-qPCR (Bio-Rad, Hercules, CA, USA). The resulting cDNA was diluted by adding $40 \mu \mathrm{L}$ of sterile distilled water.

\section{Gene expression analysis by real-time quantitative PCR}

For primer design, small amplicons ( 92 to $151 \mathrm{bp}$ ) were chosen within the first third of the cDNA sequences. To avoid amplifying genomic DNA, forward and reverse primers (20-27 nt) were designed to bind to different exons and the reverse primer was designed to hybridise across consecutive exons. Primer sequences were confirmed to hybridise to unique tomato genes using the BLAST tool (Madden 2013).

Reaction mixes $(10 \mu \mathrm{L})$ were prepared with $5 \mu \mathrm{L}$ of the SsoAdvanced SYBR Green Supermix (Bio$\mathrm{Rad}$ ), $1 \mu \mathrm{M}$ of specific primer pairs (Tables 1 and 2) and $0.8 \mu \mathrm{L}$ of cDNA. PCR amplifications were carried out in 96 well optical reaction plates on a CFX96 Touch Real-Time PCR Detection System (Bio-Rad). At least two independent RNA samples and three technical replicates were used per genotype, treatment and time-point. The thermal cycling program started with a polymerase activation step of $30 \mathrm{~s}$ at $95^{\circ} \mathrm{C}$, followed by 40 cycles $\left(5 \mathrm{~s}\right.$ at $95^{\circ} \mathrm{C}, 10 \mathrm{~s}$ at $55^{\circ} \mathrm{C}$ and $20 \mathrm{~s}$ at $72^{\circ} \mathrm{C}$ ), and a melt curve (from 65 to $95^{\circ} \mathrm{C}$, with increments of $1^{\circ} \mathrm{C}$ every $5 \mathrm{~s}$ ). Dissociation kinetic analyses of each amplified product and agarose gel loading and sequencing of the PCR product confirmed its specificity.

To quickly identify the most appropriate housekeeping gene for RT-qPCR validation, we initially selected four known tomato reference genes from a previous study: ACTIN, GAPDH, TIP4I and UBIQUITIN (Dekkers et al. 2012). Based on the probe expression data from former microarray 
experiments (Fei et al. 2011), SlACTIN7 (Solyc11 g005330), encoding the closest homologue of Arabidopsis ACTIN2, was selected as the most stable reference gene under different stress treatments.

Relative quantification of gene expression levels was performed using the comparative $\mathrm{C}_{\mathrm{t}}$ method (Schmittgen and Livak 2008). Data were represented as the relative gene expression normalised to the $\mathrm{C}_{\mathrm{t}}$ value for the tomato housekeeping gene SIACTIN7 (F: CCAAGCAGCATGAAAATTAAGG; R: CCTTTGAAATCCACATCTGCTG) according to the following calculation: fold-change $=2^{-\Delta \Delta C}$, where $\Delta \mathrm{C}_{\mathrm{t}}=\mathrm{C}_{\mathrm{t}}$ (target gene) $-\mathrm{C}_{\mathrm{t}}\left(\right.$ SlACTIN7) and $\Delta \Delta \mathrm{C}_{\mathrm{t}}=\Delta \mathrm{C}_{\mathrm{t}}$ (treatment) $-\Delta \mathrm{C}_{\mathrm{t}}$ (control). Mean of fold-change values were used for graphic representation. $\Delta \mathrm{C}_{\mathrm{T}}$ values were analysed using SPSS 21.0.0 (SPSS Inc., Cary, NC, USA) by applying the Mann-Whitney $U$ test for statistical differences between treated and control samples $(P \leq 0.05)$.

\section{Microarray hybridisation and data analysis}

Total RNA samples of A4 RIL line roots, using three biological replicates per treatment, were extracted using the SpectrumPlant Total RNA Kit (Sigma-Aldrich) including on-column DNase digestion: 200 ng of RNA was used for cDNA synthesis and Cy3-labelling using the Low Input Quick Amp Labelling Kit for One-Colour Microarray-Based Gene Expression Agilent analysis (Agilent). $1.65 \mu \mathrm{g}$ of linearly amplified and labelled cDNA was hybridised for $17 \mathrm{~h}$ at $65^{\circ} \mathrm{C}$ on $4 \times 180 \mathrm{k}$ format 60-mer oligonucleotide probes designed against the S. lycopersicum cv. Heinz 1706 build 2.4 (annotation 2.5) genome (Agilent design ID = 069672; GEO GSE79307). Each array contained $\sim 5$ probes for 34619 transcripts. Arrays were imaged using an MS200 microarray scanner using only the $480 \mathrm{~nm}$ laser using the autogain feature of the NimbleScan software. Image (tiff) files were imported into the Agilent Feature Extraction software for quality control assessment, grid alignment and expression value extraction at the probe and transcript level the RMA algorithm (Irizarry et al. 2003) used to carry out background subtraction, quantile normalisation and summarisation via median polish, and output $\log _{2}$ normalised gene expression levels (GEO GSE79307). Linear Models for Microarray Data (package limma in R) was then used to fit linear models to pairs of samples, identifying genes that contrasted the most between the experimental pairs (Smyth 2004). Transcripts were termed to be differentially expressed if they showed a Benjamini-Hochberg adjusted $P$-value $\leq$ 0.05 in the comparison between treatment and control.

\section{Results}

\section{Bibliographic review to identify conserved salt stress-responsive genes}

From existing literature, we searched microarray experiments designed to identify salt-stress regulated genes in plant species other than tomato (see 'Materials and methods'). A subset of 133 functionally validated salt-stress responsive genes was selected from these experiments and their putative tomato orthologues were identified by protein sequence similarity. This generated a list of 
107 genes, 85 of them with expression data available (Table S1). GO term analyses were performed on this dataset and genes belonging to 'response to osmotic stress' (15 genes), most of which are involved in hormone responses, mainly $\mathrm{ABA}$ and $\mathrm{JA}$, were found significantly enriched $(P<0.001)$. We then evaluated the stress-regulated expression of the selected tomato homologues by studying available microarray data (See 'Materials and methods'), and clustered them to eight groups (I to VIII) determined according to their differential expression upon salt stress and drought stress, respectively (Fig. 1a; Table S1). We found that $\sim 85 \%$ of the tomato genes selected from the literature $(n=73)$ were found differentially expressed in response to salt and/or drought stresses in these microarray experiments (Fig. 1a). Finally, a subset of 13 genes representing most of the expression clusters identified (Table S1) were chosen for functional validation by RT-qPCR as tomato salt stressresponsive biomarkers (see 'Materials and methods'; Table 1). In a first experiment, relative gene expression was assayed in young AC tomato roots after a short pulse $(6 \mathrm{~h})$ of mild salt-stress $(75 \mathrm{mM}$ $\mathrm{NaCl}$ ) or control treatment (see 'Materials and methods'). Nine of the genes studied ( $\square 70 \%$ ) displayed a slight but significant differential expression upon salt-stress in these conditions (Fig. 1b). Three of these genes (Solyc04 g078840, Solyc09 g015770 and Solyc12 g013620) displayed an increase or decrease of $>1.75$-fold after the salt treatment, suggesting that their expression was highly sensitive to the salt signal.

Next we asked whether these early salt-responsive genes identified were also influenced by ABA (see 'Materials and methods'). The Solyc04 g078840, Solyc08 g043170, Solyc11 g011050, Solyc11 g069030 and Solyc12 g013620 genes also showed altered expression upon ABA treatment (Fig. 1c), which suggests that their salt-responsiveness might be directly regulated through the ABA signalling pathway. On the other hand, the expression of the Solyc09 g015770 gene, encoding a homologue of the Arabidopsis WRKY70 (Li et al. 2004), was not significantly affected by the ABA treatment despite its higher downregulation by salt. We noted that the expression of all the other genes that were not affected by the salt-pulse in the wild-type accession, was significantly altered in the roots of the ABA-deficient flacca (flc) mutant (Sagi et al. 2002) (Fig. 1d), suggesting that their salt-induced regulation occurred in later stages.

\section{Data mining public microarray data to identify abiotic stress-responsive genes}

To identify a general set of abiotic stress biomarkers in tomato, we selected four experiments from the BioProject database (Pruitt et al. 2011) that compared microarray profiling of stressed vs nonstressed samples of different tomato cultivars with contrasting tolerance to a given abiotic stress (salt, drought, heat, and nitrogen availability; see 'Materials and methods'). Pairwise comparisons for probe gene expression among the entire dataset indicate moderate but significant correlations between salt stress and drought stress (Fig. 2a; Table S2). Hereafter, we selected 2028 genes (27.4\% of the genes represented in the array) showing differential expression $(P \leq 0.05)$ upon salt stress in either susceptible or tolerant cultivars $(5 \mathrm{~h}$ with $200 \mathrm{mM} \mathrm{NaCl}$ ) for further analysis. On the one hand, $45 \%$ 
of salt-upregulated genes and $34 \%$ of salt-downregulated genes were shared between susceptible and tolerant tomato cultivars where the most significantly-enriched GO categories for shared upregulated genes were 'ion binding' (GO:0043167) and 'response to stimulus' (GO:0050896), whereas 'tetrapyrrole binding' (GO:0046906) was significantly enriched among shared downregulated genes (Fig. 2b). On the other hand, several genes were found to have altered expression in both susceptible (Table S2) and tolerant (Fig. 2c) tomato species in response to several individual stresses.

To reveal the shared molecular mechanisms of different stress responses in tomato, we further classified the selected genes according to their differential expression $(P \leq 0.05)$ after salt stress, drought stress and heat stress either in susceptible or tolerant subtypes respectively (Fig. 2d; Table S3). We noted that the expression of genes belonging to the GO category 'response to stimulus' (GO:0050896), most of which were involved in ABA, auxin and chitin responses, were found significantly altered by one or more of these stresses (Fig. 2d; Table S3). Genes encoding integral proteins of the chloroplast envelope and thylakoids (GO:0009579) were significantly enriched among the set of genes whose expression changed by salt stress or drought stress in susceptible cultivars. Gene functions involved in tetrapyrrole binding (GO:00046906) were significantly enriched only by the salt stress (Fig. 2d; Table S3), which might be related to the alteration of the photosynthetic function through tetrapyrrole-mediated retrograde signalling (Brzezowski et al. 2015) by salt stress, similarly as it has been described for high light stress (Estavillo et al. 2011). These results suggest (i) that the quantitative regulation of the expression in a subset of these genes might account for the adaptive responses observed in tolerant species, and (ii) that multiple genes are similarly responding to different stress signals.

We then selected 501 genes whose expression was significantly changed $(P \leq 0.05)$ upon salt stress in both susceptible and tolerant tomato cultivars and that also showed moderate differential expression $(P \leq 0.10)$ upon drought stress and heat stress in susceptible cultivars (Table S4). Some of the most significantly-enriched GO categories within this dataset were 'response to stress' (GO:0006950; 77 genes; $P=3.8 \mathrm{e}-04)$ and 'response to hormone stimulus' (GO:0009725; 41 genes; $P=2.41 \mathrm{e}-05)$. A heatmap representation of the relative gene expression levels enabled us to group them into 22 clusters, ranging in size from five (cluster 4) to 40 (cluster 11) genes (Fig. 3; Table S4). Genes in clusters 1 to 11 were clearly downregulated in response to several abiotic stresses, mainly salt and drought, and the GO categories 'regulation of G2/M transition of mitotic cell cycle' (GO:0010389; seven genes; $P$ value $=2.1 \mathrm{e}-04)$ and 'chlorophyll biosynthetic process' $(\mathrm{GO}: 0015995$; four genes; $P=$ 3.4e-04) were found over-represented in these clusters. Conversely, genes in clusters 12 to 22 were upregulated by stress and some of the most significantly-enriched GO categories were 'response to stress' (47 genes; $P=1.1 \mathrm{e}-04$ ) and 'cellular amino acid catabolic process' (GO:0009063; eight genes; $P=1.9 \mathrm{e}-06)$. Other genes belonging to the categories 'ethylene-activated signalling pathway' (GO:0009873; seven genes; $P=7.4 \mathrm{e}-04$ ), 'response to chitin' (GO:0010200; eight genes; $P=2.4 \mathrm{e}-$ 
04), and 'response to ABA stimulus' (GO:0009737; 13 genes; $P=1.3 \mathrm{e}-04$ ) were also found commonly upregulated by salt and drought stress.

Fourteen genes across a range of the expression clusters shown in Fig. 3 were selected based on the following criteria: (1) their putative encoding proteins belonged to some of the most GO-enriched categories found, and (2) they were expressed in roots in previous microarray experiments (see Materials and methods; Table 2). Their relative gene expression levels were tested in young roots of the AC background after a pulse of salt-stress $(6 \mathrm{~h}, 75 \mathrm{mM} \mathrm{NaCl})$ and compared with that of controltreated plants (see 'Materials and methods'). The expression of 11 of the studied genes ( 80\%) was found significantly differentially regulated by the salt treatment (Fig. 4A). Six genes (Solyc01 g107730, Solyc01 g111660, Solyc02 g069490, Solyc03 g096460, Solyc05 g007180 and Solyc07 g043130) were downregulated, whereas the other five (Solyc01 g079200, Solyc02 g084850, Solyc03 g006880, Solyc03 g095510 and Solyc07 g049530) were upregulated after the salt pulse. Our qPCR results were mostly in agreement with the results from previous microarray data and confirmed that the selected genes might be used as early-responsive, root-specific and salt stress-regulated biomarkers. In the other three genes tested in our study, the differences in relative expression levels between the two treatments were not statistically significant (Fig. 4a), although two of them showed a significant downregulation in the ABA-deficient flacca mutant (Fig. 4b). Next, we tested whether the expression of these 11 salt stress-regulated genes was also dependent on the ABA signal (Fig. 4c). Only four of these genes (Solyc02 g084850, Solyc03 g006880, Solyc03 g095510 and Solyc07 g049530) displayed differential expression upon $1 \mu \mathrm{M}$ ABA treatment. Among those, Solyc07 g049530 encodes a putative ACC oxidase involved in ethylene biosynthesis and whose Arabidopsis orthologue, At1 g05010, was upregulated under drought stress (Winter et al. 2007). Another gene strongly upregulated by salt and ABA was Solyc02 g084850, encoding the Tas.14 dehydrin (Godoy et al. 1994).

\section{Verification of selected genes as multiple abiotic stress-responsive biomarkers}

We next asked whether the 28 stress-responsive genes selected in previous sections for RT-qPCR validation (Tables 1,2) could also be used to quantify the responses of the root system to other stresses, such as drought or nutrient deficiency. To this end, we gathered microarray data obtained from a multi-stress experiment using RIL A4 derived from S. lycopersicum var. cerasiforme line 'E9' and S. pimpinellifolium line 'L5' cross (Estañ et al. 2009). This line was grown in either combined low phosphorus (low P) and drought conditions or optimal conditions (see 'Materials and methods'). Fourteen of the stress-responsive genes selected were found to be significantly $(P<0.05)$ differentially expressed in low $\mathrm{P}$ and drought conditions compared with control plants (Table S5). Only $18 \%$ of the genes on the array were found differentially expressed by the combined stress treatment applied, whereas $50 \%$ of the selected genes (14 genes out of 28 ) were responsive to the combined stress treatment, hence, we reasoned that the genes selected were significantly enriched 
among the microarray dataset, confirming their value as root-specific multistress biomarkers.

Additionally, we collected roots from 10-week-old plants (AC) that were grown in soil during 11 days in salt $(100 \mathrm{mM} \mathrm{NaCl})$ or control conditions (Fig. 5a) and studied the expression of several of the stress-responsive genes validated previously (Fig. 5b). The majority (seven) of genes were similarly upregulated by single (salt) or combined (low P and drought) stresses: GA2ox-3, GH3.3, Tas.14, KIN2, $A R E B 1, W R K Y 70$, and JA2. We noted that three of the genes selected based on their differential expression after a pulse of salt treatment (CYCD3;2, DIM and PLAT) were not significantly affected by the long-term stress conditions assayed here, suggesting that these genes might be involved in the early responses to stress. Several the selected genes whose expression was differentially regulated by several stresses were also affected by a pulse of $\mathrm{ABA}$, while others did not respond to our $\mathrm{ABA}$ treatment (Figs 1c, 4c, 5c).

\section{Discussion}

In our first approach, we found that the expression of nine putative salt-responsive genes in tomato, identified from expression data gathered from other species, was significantly altered upon a pulse of salt stress ( $\sim 70 \%$ of the genes assayed). These results validate our literature-mining strategy to identify salt-responsive genes in tomato roots through comparative transcriptomic profiling in different plant species challenged by high salt conditions. Several early salt-responsive genes identified in this way were also influenced by ABA. Indeed, Solyc04 g078840 encodes AREB1, a transcription factor induced by drought and salinity through a canonical ABA-responsive pathway, and whose overexpression confers increased tolerance to salt and water stress in tomato (Orellana et al. 2010). Notably, Solyc12 g013620 encodes the JA2 transcription factor of the NAC family, which has been recently shown to be activated by $\mathrm{ABA}$ and that mediates stomatal closure in rice (Du et al. 2014). We have shown here for the first time that the tomato $J A 2$ gene is an early salt-stress and ABA-responsive gene in roots, which suggests that the hormonal crosstalk between ABA and JA might also regulate specific adaptive responses under salt stress in tomato. Recent studies have implicated some WRKYs in the negative regulation of the oxidative stress responses (Chen et al. 2010). Indeed, wrky54 wrky70 double mutants exhibited enhanced tolerance to osmotic stress in Arabidopsis, which was likely caused by higher stomatal closure in these mutants (Sun et al. 2010). Although the rapid downregulation found in roots for the WRKY70 homologue (Solyc09 g015770) after the salt treatment might indirectly contribute to osmotic stress adaptation through the regulation of stomatal conductance, additional experiments are required to assess whether the WRKY protein encoded by this gene plays a similar role to that proposed for its Arabidopsis counterpart ( $\mathrm{Li}$ et al. 2013). The expression of other salt-induced genes was significantly altered only at later stages. An example is Solyc01 g067710, which encodes a $\mathrm{Na}^{+} / \mathrm{H}^{+}$exchanger that has been recently proposed to play a role in long-term $\mathrm{Na}^{+}$accumulation in the roots of salt-treated tomato accessions (Almeida et al. 2014). Our results suggest that an evolutionary conserved set of salt-stress responsive genes might control a 
similar range of physiological, metabolic and cellular processes in different species. Indeed, salinity stress involves similar changes in different plant species involving various physiological and metabolic processes, such as ion salt homeostasis, biosynthesis of osmoprotectants, antioxidant regulation and hormone modulation (Gupta and Huang 2014). Through appropriate primer design, the genes identified in this work could be used as general salt-stress biomarkers to rapidly evaluate the response of salt-tolerant cultivars and wild species for which not sufficient genetic information is available, such as Asparagus officinalis and Spergularia marina among others.

Recent work in Arabidopsis and rice found that a subset of downstream responses was shared between biotic and abiotic stresses (Sham et al. 2014; Zhang et al. 2015). Consistent with the hypothesis of shared signalling components between biotic and abiotic stresses, chitinase-defective mutants of Arabidopsis are also hypersensitive to salt, drought and heat stress due to cell wall alterations that indirectly impair membrane integrity (Kwon et al. 2007). By comparing the responses of Arabidopsis to a variety of abiotic and biotic stresses, a common 'universal stress response transcriptome' was previously identified and that contained conserved pathways, such as those related to MAPK cascades, vesicle transport, mitochondrial function and transcription machinery (Ma and Bohnert 2007). In addition, several ABA- and JA-regulated genes were found specifically upregulated in roots in response to several stresses in this species (Ma and Bohnert 2007). We found that a large proportion of differentially expressed genes in tomato were specifically regulated upon salt stress or drought stress. These results suggest that, mirroring findings in Arabidopsis, the different abiotic stresses activated similar signal transduction pathways and metabolic responses in tomato roots (Fujita et al. 2006). Additional experiments will be needed to assess whether some signalling components between biotic and abiotic stresses are also shared in tomato.

We have experimentally verified by RT-qPCR that 20 of the genes selected from tomato microarray data displayed differential expression in tomato roots after a pulse of mild salt stress, suggesting their utility as root-autonomous salt stress-responsive biomarkers. Our results revealed the ABA-dependent specific upregulation of the gene encoding an ACC oxidase in tomato roots (Solyc07 g049530) and suggested an inhibitory role of increased ethylene levels on primary root growth in response to a mild salt stress in an analogous way to that proposed in Arabidopsis (Luo et al. 2014). The availability of tomato mutants impaired in ethylene biosynthesis or ethylene perception (Negi et al. 2010) will allow testing this hypothesis. Another gene strongly upregulated by salt and ABA was Solyc02 g084850, encoding the Tas.14 dehydrin (Godoy et al. 1994). Tomato plants overexpressing Tas. 14 achieved improved long-term drought and salinity tolerance without affecting plant growth under non-stress conditions, which might be associated with their ability to rapidly increase ABA levels after perceiving drought stress (Muñoz-Mayor et al. 2012).

As it was previously shown in Arabidopsis, salt stress transiently inhibited root growth through cell cycle inhibition in the meristem and when the meristem reached the appropriate size for the given 
conditions, cell cycle duration returned to its default (West et al. 2004). Our results on CYCD3;2 (Solyc01 g107730) expression suggest that similar regulation might take place in tomato roots in response to salt stress. Among the early upregulated genes by salt stress, Solyc01 g079200, encoding a putative GA2 oxidase-3 (GA2ox-3) involved in GA catabolism (Rieu et al. 2008), was particularly interesting. A recent report in hybrid poplar (Populus tremula $\times$ Populus alba) identified GA2oxencoding genes as targets mediating the shoot growth inhibition and physiological adaptation in response to drought stress in these species (Zawaski and Busov 2014). Our results are in agreement with the hypothesis that GA metabolism and signalling constitute a major regulatory circuit mediating growth restraint and physiological adaptation to unfavourable conditions. However, Solyc01 g111660, which encodes the PIP1.2 aquaporin (Reuscher et al. 2013), was found significantly downregulated by salt stress. The expression of other tomato aquaporins in response to salt stress has not been so far investigated, but in Arabidopsis aquaporin gene expression in roots dramatically decreased between 2 and $4 \mathrm{~h}$ after the salt treatment (Boursiac et al. 2005). It has been proposed that coordinated transcriptional downregulation and subcellular localisation of several aquaporins might contribute to the short- and long-term regulation of root water transport in response to salt stress, by limiting water symplastic transport (and hence transpiration) which prevents fast wilting under water stress (Boursiac et al. 2005). Besides, although the GH3.3 (Solyc01 g107390) gene has been previously shown to be induced by salt stress in tomato (Kumar et al. 2012), its Arabidopsis homologue is known to be required for adventitious root development by modulating JA catabolism downstream of the auxin signal in this species (Gutierrez et al. 2012). Hence, further experiments will be required to uncover the link between salinity stress and GH3.3 expression and whether this gene affects root architecture in tomato. We found that most of the studied genes were similarly upregulated by single (salt) or combined (low P and drought) stresses. In contrast, P5CS was significantly upregulated only by salt. Indeed, proline accumulation is a common physiological adaptive response to salinity in many plant species. Proline is mainly synthesised from L-glutamic acid by pyrroline-5-carboxylate synthetase (P5CS) (Verbruggen and Hermans 2008), and P5CS expression has been shown to be positively regulated by salt in rice (Bagdi et al. 2015).

In conclusion, by screening available microarray data obtained from different plant species and under different stresses, we identified several genes showing differential expression in tomato roots in response to one or several stresses. We validated 10 of these genes as reliable biomarkers whose expression levels are related to signalling pathways involved in adaptive stress responses. These genes could be used to evaluate, at the molecular level, the stress responses of tomato cultivars that differ in stress tolerance. Due to conservation of genes and their downstream responses, they could also be used to evaluate the stress responses in different species where full transcriptomic information is not yet available. 


\section{Acknowledgements}

We thank Ángel Nadal and Iván Quesada (Universidad Miguel Hernández, Elche, Spain) for the use of RT-

qPCR equipment and María de los Ángeles Fernández López for technical assistance. We are especially indebted to Ian Dodd (University of Lancaster, Lancaster, UK) and María José Asins (Instituto Valenciano de

Investigaciones Agrarias, Valencia, Spain) for providing seeds of the Ailsa Craig, flacca mutant and the parental line for RIL A4, respectively, and to Aquilino Sanchez (Unigenia Bioscience, Murcia, Spain) for providing grafted transplants of RIL A4. This work was supported by the European Commission (ROOTOPOWER; FP7KBBE -2011-5-289365) and by the 'Programa Gerónimo Forteza'· of the Generalitat Valenciana (FPA/2015/016). A.F.-A., C.M.-A. and Z.K. held research contracts from ROOTOPOWER. 


\section{References}

Achuo EA, Prinsen E, Hofte M (2006) Influence of drought, salt stress ans abscisic acid on the resistance of tomato to Botrytis cinerea and Oidium neolycopersici. Plant Pathology 55, 178-186. doi:10.1111/j.1365-3059.2006.01340.x

Almeida P, Feron R, de Boer GJ, de Boer AH (2014) Role of Na+, K+, Cl-, proline and sucrose concentrations in determining salinity tolerance and their correlation with the expression of multiple genes in tomato. AoB Plants 6, doi:10.1093/aobpla/plu039

Bagdi DL, Shaw BP, Sahu BB, Purohit GK (2015) Real time PCR expression analysis of gene encoding p5cs enzyme and proline metabolism under $\mathrm{NaCI}$ salinity in rice. Journal of Environmental Biology 36, 955-961.

Barrett T, Wilhite SE, Ledoux P, Evangelista C, Kim IF, Tomashevsky M, Marshall KA, Phillippy KH, Sherman PM, Holko M, Yefanov A, Lee H, Zhang N, Robertson CL, Serova N, Davis S, Soboleva A (2013) NCBI GEO: archive for functional genomics data sets - update. Nucleic Acids Research 41, D991-D995. doi:10.1093/nar/gks1193

<bok>Bates B, Kundzewicz ZW, Wu S, Palutikof J (2008) 'Climate change and water.' (IPCC Secretariat: Geneva, Switzerland) $</$ bok $>$

Benjamini Y, Hochberg Y (1995) Controlling the false discovery rate: a practical and powerful approach to multiple testing. Journal of the Royal Statistical Society. Series B. Methodological 57, 289-300.

Boursiac Y, Chen S, Luu DT, Sorieul M, van den Dries N, Maurel C (2005) Early effects of salinity on water transport in Arabidopsis roots. Molecular and cellular features of aquaporin expression. Plant Physiology 139, 790-805. doi:10.1104/pp.105.065029

Bowler C, Fluhr R (2000) The role of calcium and activated oxygens as signals for controlling crosstolerance. Trends in Plant Science 5, 241-246. doi:10.1016/S1360-1385(00)01628-9

Brzezowski P, Richter AS, Grimm B (2015) Regulation and function of tetrapyrrole biosynthesis in plants and algae. Biochimica et Biophysica Acta 1847, 968-985. doi:10.1016/j.bbabio.2015.05.007

Cardinale F, Meskiene I, Ouaked F, Hirt H (2002) Convergence and divergence of stress-induced mitogen-activated protein kinase signaling pathways at the level of two distinct mitogen-activated protein kinase kinases. The Plant Cell 14, 703-711.

Chen H, Lai Z, Shi J, Xiao Y, Chen Z, Xu X (2010) Roles of Arabidopsis WRKY18, WRKY40 and WRKY60 transcription factors in plant responses to abscisic acid and abiotic stress. BMC Plant Biology 10, 281. doi:10.1186/1471-2229-10-281

Cotsaftis O, Plett D, Johnson AA, Walia H, Wilson C, Ismail AM, Close TJ, Tester M, Baumann U (2011) Root-specific transcript profiling of contrasting rice genotypes in response to salinity stress. Molecular Plant 4, 25-41. doi:10.1093/mp/ssq056

Dekkers BJ, Willems L, Bassel GW, van Bolderen-Veldkamp RP, Ligterink W, Hilhorst HW, Bentsink L (2012) Identification of reference genes for RT-qPCR expression analysis in Arabidopsis and tomato seeds. Plant \& Cell Physiology 53, 28-37. doi:10.1093/pcp/pcr113

Du H, Chang Y, Huang F, Xiong L (2014) GID1 modulates stomatal response and submergence tolerance involving abscisic acid and gibberellic acid signaling in rice. Journal of Integrative Plant Biology 57, 954-968. doi:10.1111/jipb.12313 
Estañ MT, Villalta I, Bolarín MC, Carbonell EA, Asins MJ (2009) Identification of fruit yield loci controlling the salt tolerance conferred by solanum rootstocks. Theoretical and Applied Genetics 118, 305-312. doi:10.1007/s00122-008-0900-6

Estavillo GM, Crisp PA, Pornsiriwong W, Wirtz M, Collinge D, Carrie C, Giraud E, Whelan J, David P, Javot H, Brearley C, Hell R, Marin E, Pogson BJ (2011) Evidence for a SAL1-PAP chloroplast retrograde pathway that functions in drought and high light signaling in Arabidopsis. The Plant Cell 23, 3992-4012. doi:10.1105/tpc.111.091033

Fei Z, Joung JG, Tang X, Zheng Y, Huang M, Lee JM, McQuinn R, Tieman DM, Alba R, Klee HJ, Giovannoni JJ (2011) Tomato Functional Genomics Database: a comprehensive resource and analysis package for tomato functional genomics. Nucleic Acids Research 39, D1156-D1163. doi:10.1093/nar/gkq991

Fujita M, Fujita Y, Noutoshi Y, Takahashi F, Narusaka Y, Yamaguchi-Shinozaki K, Shinozaki K (2006) Crosstalk between abiotic and biotic stress responses: a current view from the points of convergence in the stress signaling networks. Current Opinion in Plant Biology 9, 436-442. doi:10.1016/j.pbi.2006.05.014

Fujita Y, Fujita M, Shinozaki K, Yamaguchi-Shinozaki K (2011) ABA-mediated transcriptional regulation in response to osmotic stress in plants. Journal of Plant Research 124, 509-525. doi:10.1007/s 10265-011-0412-3

Godoy JA, Lunar R, Torres-Schumann S, Moreno J, Rodrigo RM, Pintor-Toro JA (1994) Expression, tissue distribution and subcellular localization of dehydrin TAS14 in salt-stressed tomato plants. Plant Molecular Biology 26, 1921-1934. doi:10.1007/BF00019503

Grant MR, Jones JD (2009) Hormone (dis)harmony moulds plant health and disease. Science 324, 750-752. doi:10.1126/science. 1173771

Gupta B, Huang B (2014) Mechanism of salinity tolerance in plants: physiological, biochemical, and molecular characterization. International Journal of Genomics 2014, 701596. doi:10.1155/2014/701596

Gutierrez L, Mongelard G, Flokova K, Pacurar DI, Novak O, Staswick P, Kowalczyk M, Pacurar M, Demailly H, Geiss G, Bellini C (2012) Auxin controls Arabidopsis adventitious root initiation by regulating jasmonic acid homeostasis. The Plant Cell 24, 2515-2527. doi:10.1105/tpc.112.099119

Huang J, Lu X, Yan H, Chen S, Zhang W, Huang R, Zheng Y (2012) Transcriptome characterization and sequencing-based identification of salt-responsive genes in Millettia pinnata, a semi-mangrove plant. DNA Research 19, 195-207. doi:10.1093/dnares/dss004

Irizarry RA, Hobbs B, Collin F, Beazer-Barclay YD, Antonellis KJ, Scherf U, Speed TP (2003) Exploration, normalization, and summaries of high density oligonucleotide array probe level data. Biostatistics 4, 249-264. doi:10.1093/biostatistics/4.2.249

Iyer-Pascuzzi AS, Jackson T, Cui H, Petricka JJ, Busch W, Tsukagoshi H, Benfey PN (2011) Cell identity regulators link development and stress responses in the Arabidopsis root. Developmental Cell 21, 770-782. doi:10.1016/j.devcel.2011.09.009

Joung JG, Corbett AM, Fellman SM, Tieman DM, Klee HJ, Giovannoni JJ, Fei Z (2009) Plant MetGenMAP: an integrative analysis system for plant systems biology. Plant Physiology 151, 17581768. doi:10.1104/pp.109.145169

Kumar R, Agarwal P, Tyagi AK, Sharma AK (2012) Genome-wide investigation and expression analysis suggest diverse roles of auxin-responsive GH3 genes during development and response to 
different stimuli in tomato (Solanum lycopersicum). Molecular Genetics and Genomics 287, 221-235. doi:10.1007/s00438-011-0672-6

Kwon Y, Kim SH, Jung MS, Kim MS, Oh JE, Ju HW, Kim KI, Vierling E, Lee H, Hong SW (2007) Arabidopsis hot 2 encodes an endochitinase-like protein that is essential for tolerance to heat, salt and drought stresses. The Plant Journal 49, 184-193. doi:10.1111/j.1365-313X.2006.02950.x

Li J, Brader G, Palva ET (2004) The WRKY70 transcription factor: a node of convergence for jasmonate-mediated and salicylate-mediated signals in plant defense. The Plant Cell 16, 319-331. doi:10.1105/tpc. 016980

Li J, Besseau S, Törönen P, Sipari N, Kollist H, Holm L, Palva ET (2013) Defense-related transcription factors WRKY70 and WRKY54 modulate osmotic stress tolerance by regulating stomatal aperture in Arabidopsis. New Phytologist 200, 457-472. doi:10.1111/nph.12378

Luo X, Chen Z, Gao J, Gong Z (2014) Abscisic acid inhibits root growth in Arabidopsis through ethylene biosynthesis. The Plant Journal 79, 44-55. doi:10.1111/tpj.12534

Ma S, Bohnert HJ (2007) Integration of Arabidopsis thaliana stress-related transcript profiles, promoter structures, and cell-specific expression. Genome Biology 8, R49. doi:10.1186/gb-2007-8-4r49

Madden, T (2013) 'The NCBI handbook.'

Mittler R (2006) Abiotic stress, the field environment and stress combination. Trends in Plant Science 11, 15-19. doi:10.1016/j.tplants.2005.11.002

Mittler R, Blumwald E (2010) Genetic engineering for modern agriculture: challenges and perspectives. Annual Review of Plant Biology 61, 443-462. doi:10.1146/annurev-arplant-042809112116

Mohr PG, Cahill DM (2003) Abscisic acid influences the susceptibility of Arabidopsis thaliana to Pseudomonas syringae pv. tomato and Peronospora parasitica. Functional Plant Biology 30, 461-469. doi:10.1071/FP02231

Monforte AJ, Asins MJ, Carbonell EA (1997) Salt tolerance in Lycopersicon species V. Does genetic variability at quantitative trait loci affect their analysis? Theoretical and Applied Genetics 95, 284293. doi:10.1007/s001220050561

Muñoz-Mayor A, Pineda B, Garcia-Abellán JO, Antón T, Garcia-Sogo B, Sanchez-Bel P, Flores FB, Atarés A, Angosto T, Pintor-Toro JA, Moreno V, Bolarin MC (2012) Overexpression of dehydrin tas 14 gene improves the osmotic stress imposed by drought and salinity in tomato. Journal of Plant Physiology 169, 459-468. doi:10.1016/j.jplph.2011.11.018

Murashige T, Skoog F (1962) A revised medium for rapid growth and bioassays with tobacco tissue cultures. Physiologia Plantarum 15, 473-497. doi:10.1111/j.1399-3054.1962.tb08052.x

Negi S, Sukumar P, Liu X, Cohen JD, Muday GK (2010) Genetic dissection of the role of ethylene in regulating auxin-dependent lateral and adventitious root formation in tomato. The Plant Journal 61, 315. doi:10.1111/j.1365-313X.2009.04027.x

Orellana S, Yañez M, Espinoza A, Verdugo I, González E, Ruiz-Lara S, Casaretto JA (2010) The transcription factor SIAREB1 confers drought, salt stress tolerance and regulates biotic and abiotic stress-related genes in tomato. Plant, Cell \& Environment 33, 2191-2208. doi:10.1111/j.1365-

3040.2010.02220.x 
Ouyang B, Yang T, Li H, Zhang L, Zhang Y, Zhang J, Fei Z, Ye Z (2007) Identification of early salt stress response genes in tomato root by suppression subtractive hybridization and microarray analysis. Journal of Experimental Botany 58, 507-520. doi:10.1093/jxb/erl258

Pieterse CM, Leon-Reyes A, Van der Ent S, Van Wees SC (2009) Networking by small-molecule hormones in plant immunity. Nature Chemical Biology 5, 308-316. doi:10.1038/nchembio. 164

Pnueli L, Hallak-Herr E, Rozenberg M, Cohen M, Goloubinoff P, Kaplan A, Mittler R (2002) Molecular and biochemical mechanisms associated with dormancy and drought tolerance in the desert legume Retama raetam. The Plant Journal 31, 319-330. doi:10.1046/j.1365-313X.2002.01364.x

Pruitt, K, Clark, K, Tatusova, T, Mizrachi, I (2011) ‘BioProject Help.’

Rensink WA, Iobst S, Hart A, Stegalkina S, Liu J, Buell CR (2005) Gene expression profiling of potato responses to cold, heat, and salt stress. Functional \& Integrative Genomics 5, 201-207. doi:10.1007/s10142-005-0141-6

Reuscher S, Akiyama M, Mori C, Aoki K, Shibata D, Shiratake K (2013) Genome-wide identification and expression analysis of aquaporins in tomato. PLoS One 8, e79052.

doi:10.1371/journal.pone.0079052

Rieu I, Eriksson S, Powers SJ, Gong F, Griffiths J, Woolley L, Benlloch R, Nilsson O, Thomas SG, Hedden P, Phillips AL (2008) Genetic analysis reveals that C19-GA 2-oxidation is a major gibberellin inactivation pathway in Arabidopsis. The Plant Cell 20, 2420-2436. doi:10.1105/tpc.108.058818

Rizhsky L, Liang H, Mittler R (2002) The combined effect of drought stress and heat shock on gene expression in tobacco. Plant Physiology 130, 1143-1151. doi:10.1104/pp.006858

Rizhsky L, Liang H, Shuman J, Shulaev V, Davletova S, Mittler R (2004) When defense pathways collide. The response of Arabidopsis to a combination of drought and heat stress. Plant Physiology 134, 1683-1696. doi:10.1104/pp.103.033431

Ruzicka DR, Barrios-Masias FH, Hausmann NT, Jackson LE, Schachtman DP (2010) Tomato root transcriptome response to a nitrogen-enriched soil patch. BMC Plant Biology 10, 75. doi:10.1186/1471-2229-10-75

Sagi M, Scazzocchio C, Fluhr R (2002) The absence of molybdenum cofactor sulfuration is the primary cause of the flacca phenotype in tomato plants. The Plant Journal 31, 305-317.

doi:10.1046/j.1365-313X.2002.01363.x

Schmittgen TD, Livak KJ (2008) Analyzing real-time PCR data by the comparative C(T) method. Nature Protocols 3, 1101-1108. doi:10.1038/nprot.2008.73

Sham A, Al-Azzawi A, Al-Ameri S, Al-Mahmoud B, Awwad F, Al-Rawashdeh A, Iratni R, AbuQamar S (2014) Transcriptome analysis reveals genes commonly induced by Botrytis cinerea infection, cold, drought and oxidative stresses in Arabidopsis. PLoS One 9, e113718. doi:10.1371/journal.pone. 0113718

Smyth GK (2004) Linear models and empirical bayes methods for assessing differential expression in microarray experiments. Statistical Applications in Genetics and Molecular Biology 3, Article3.

Sun W, Xu X, Zhu H, Liu A, Liu L, Li J, Hua X (2010) Comparative transcriptomic profiling of a salttolerant wild tomato species and a salt-sensitive tomato cultivar. Plant \& Cell Physiology 51, 9971006. doi:10.1093/pcp/pcq056 
The Tomato Genome Consortium (2012) The tomato genome sequence provides insights into fleshy fruit evolution. Nature 485, 635-641. doi:10.1038/nature11119

Verbruggen N, Hermans C (2008) Proline accumulation in plants: a review. Amino Acids 35, $753-$ 759. doi:10.1007/s00726-008-0061-6

West G, Inzé D, Beemster GT (2004) Cell cycle modulation in the response of the primary root of Arabidopsis to salt stress. Plant Physiology 135, 1050-1058. doi:10.1104/pp.104.040022

Wiese J, Kranz T, Schubert S (2004) Induction of pathogen resistance in barley by abiotic stress. Plant Biology 6, 529-536. doi:10.1055/s-2004-821176

Winter D, Vinegar B, Nahal H, Ammar R, Wilson GV, Provart NJ (2007) An 'electronic fluorescent pictograph' browser for exploring and analyzing large-scale biological data sets. PLoS One 2, e718. doi:10.1371/journal.pone.0000718

Xiong L, Yang Y (2003) Disease resistance and abiotic stress tolerance in rice are inversely modulated by an abscisic acid-inducible mitogen-activated protein kinase. The Plant Cell 15, 745-759.

doi: $10.1105 /$ tpc. 008714

Yao D, Zhang X, Zhao X, Liu C, Wang C, Zhang Z, Zhang C, Wei Q, Wang Q, Yan H, Li F, Su Z (2011) Transcriptome analysis reveals salt-stress-regulated biological processes and key pathways in roots of cotton (Gossypium hirsutum L.). Genomics 98, 47-55. doi:10.1016/j.ygeno.2011.04.007

Zawaski C, Busov VB (2014) Roles of gibberellin catabolism and signaling in growth and physiological response to drought and short-day photoperiods in Populus trees. PLoS One 9, e86217. doi:10.1371/journal.pone.0086217

Zhang YP, E ZG, Jiang H, Wang L, Zhou J, Zhu DF (2015) A comparative study of stress-related gene expression under single stress and intercross stress in rice. Genetics and Molecular Research 14, 3702-3717. doi:10.4238/2015.April.17.20

Zhu JK (2002) Salt and drought stress signal transduction in plants. Annual Review of Plant Biology 53, 247-273. doi:10.1146/annurev.arplant.53.091401.143329

Manuscript received 23 December 2015, accepted 18 April 2016

Fig. 1. Experimental validation of conserved salt-stress responsive genes in tomato (Solanum lycopersicum) roots. (a) A four-way Venn diagram showing the number of tomato homologues of conserved salt-stress genes from other species that showed differential expression by salt and drought stress from available microarray data. For 12 of the 85 genes selected there was no significant alteration of expression in this dataset. $(b, c)$ Real-time PCR quantification of the expression of selected genes in tomato roots in response to $(b)$ salt stress or $(c)$ ABA treatment. $(d)$ Real-time PCR quantification of the expression of selected genes in wild-type and flc roots.

Relative expression levels were normalised to the SIACTIN7 gene. Bars indicate the relative expression levels (2 ${ }^{\Delta \Delta \mathrm{Ct}}$ method $) \pm$ s.e. Significant differences between treatments are indicated: ${ }^{*}, P \leq 0.05(75 \mathrm{mM} \mathrm{NaCl}$ or $1 \mu \mathrm{M}$ ABA vs mock) or genotypes ( $f l c$ vs AC).

Fig. 2. Identification of abiotic stress-responsive genes from public microarray data. (a) Scatter plots of differentially expressed genes (DEGs) from microarray experiments of different abiotic stresses in tomato species. Numbers indicate the coefficient of determination $\left(r^{2}\right)$ of simple linear regression between pairs of experiments. (b) Two-way Venn diagram showing the common DEGs between salt sensitive (red) and salt- 
tolerant (green) tomato species. (c) Scatter plots of DEGs in response to different stresses in tolerant tomato species. $(d)$ Gene ontology (GO) enrichment analysis of shared DEGs between different stresses (salt-, droughtand heat-stress). Numbers between brackets in $(b)$ and $(d)$ indicate the $P$-value of the GO term shown.

Fig. 3. Clustering of the DEGs in response to several abiotic stresses in tomato. Each row in the column corresponds to a single gene, and the colour scale corresponds to the ratio of expression from red (downregulated genes) to white (upregulated genes). Euclidean distance matrixes between genes (rows) and experiments (columns) were calculated to build the dendrograms. Numbers in the dendrogram indicate the gene clusters identified (see text).

Fig. 4. Experimental validation of abiotic stress-responsive genes in tomato roots. (a) Real-time PCR quantification of the expression of selected genes in tomato roots in response to salt stress. (b) Real-time PCR quantification of the expression of selected genes in wild-type and flc roots. (c) Real-time PCR quantification of the expression of selected genes in tomato roots in response to ABA. Relative expression levels were normalised to the SlACTIN7 gene. Bars indicate the relative expression levels $\left(2^{-\Delta \Delta \mathrm{Ct}}\right.$ method $) \pm$ s.e. Significant differences between treatments are indicated: *, $P \leq 0.05)(75 \mathrm{mM} \mathrm{NaCl}$ or $1 \mu \mathrm{M}$ ABA vs mock) or genotypes (flc vs AC).

Fig. 5. Experimental validation of biomarkers for abiotic stress responses in tomato roots. (a) Representative scanned images of wild-type tomato roots grown in control conditions and $100 \mathrm{mM} \mathrm{NaCl}$ for 11 days. Scale bar: $1 \mathrm{~cm}$. (b) Real-time PCR quantification of the expression of selected biomarkers in tomato roots in response to long-term salt stress (red bars) compared with microarray data from combined drought and low phosphorus conditions (orange bars). The blue bar represents the non-stressed treatment and is set to unity for each of the two experiments. Relative expression levels were normalised as regards to that of the SlACTIN7 gene. Bars indicate the relative expression levels $\left(2^{-\Delta \Delta \mathrm{Ct}}\right.$ method). Significant differences between treatments are indicated: *, $P \leq 0.05$ ). Abbreviations: AC, Ailsa Craig; A4, tomato RIL (c) Proposed model for the selected biomarkers' expression in response to abiotic stresses and their putative role in adaptive stress responses. 
Table 1. Putative tomato salt-responsive genes selected from the literature review

\begin{tabular}{|c|c|c|c|c|c|}
\hline \multirow{2}{*}{$\begin{array}{l}\text { Gene locus } \\
\text { Solyc01 } \\
\text { g067710 }\end{array}$} & \multirow{2}{*}{$\begin{array}{c}\text { Protein product (synonyms) } \\
\begin{array}{c}\text { (Sodium/potassium)/proton } \\
\text { exchanger } 3 \text { (NHX3) }\end{array}\end{array}$} & \multicolumn{2}{|c|}{ Oligonucleotide sequences $\left(5^{\prime}\right.$ to $\left.3^{\prime}\right)$} & \multicolumn{2}{|c|}{$\begin{array}{l}\text { Product Cluster } \\
\text { (bp) }\end{array}$} \\
\hline & & CTTTGCACTGGAGTTGTCATTC & TCACCTGAAACCTGCCAGCAT & 130 & II \\
\hline $\begin{array}{l}\text { Solyc01 } \\
\text { g094690 }\end{array}$ & $\begin{array}{c}\text { Water channel protein (PIP1.2, } \\
\text { AQP2) }\end{array}$ & TGTATTGACTGTTATGGGTTATTC & GTTAATGTGTCCACCTGATATG & 139 & $\mathrm{~V}$ \\
\hline $\begin{array}{l}\text { Solyc02 } \\
\text { g084240 }\end{array}$ & H1 histone-like protein & CAAGGTTAAGGAGCAGGCTTC & AGAGCCTCCTTAATCATCTGAA & 135 & II \\
\hline $\begin{array}{l}\text { Solyc04 } \\
\text { g078840 }\end{array}$ & BZIP transcription factor (AREB1) & GGAGAATGATAAAAAATAGAGAGTC & CATTTCTAАCATTTCTTCCTGTTTC & 143 & II \\
\hline $\begin{array}{l}\text { Solyc06 } \\
\text { g005170 }\end{array}$ & $\begin{array}{c}\text { Mitogen-activated protein kinase } 3 \\
\text { (MPK3) }\end{array}$ & GAATGAGATGGTTGCAGTTAAG & CATCTCTTAAACCAATGACGTTTTC & 128 & I \\
\hline $\begin{array}{l}\text { Solyc06 } \\
\text { g048410 }\end{array}$ & Superoxide dismutase & GCTTACAATGGAGAACCCAAAAG & TGAGGCTCCAAAGCATCCATTG & 115 & VI \\
\hline $\begin{array}{l}\text { Solyc07 } \\
\text { g062970 }\end{array}$ & $\begin{array}{l}\text { Serine/threonine phosphatase family } \\
\text { protein (DIG3) }\end{array}$ & GAACTTGGTCTATTTGCAATATTTG & GCCCAGAAGTTAGGCTCATTG & 107 & II \\
\hline $\begin{array}{l}\text { Solyc08 } \\
\text { g043170 }\end{array}$ & $\begin{array}{c}\text { Delta 1-pyrroline-5-carboxylate } \\
\text { synthetase (P5CS, PRO2) }\end{array}$ & TTAGAGATCCAGATTTTAGGAGAC & CAAAATATTCCAGAAGAGTCCTCAT & 139 & VII \\
\hline $\begin{array}{l}\text { Solyc08 } \\
\text { g081540 }\end{array}$ & $\begin{array}{c}\text { 1-aminocyclopropane-1-carboxylate } \\
\text { synthase (ACS1A) }\end{array}$ & CCAAGAATGGATGGTGAATAAT & TAAACCTTGCAACTGCTTGTCTA & 131 & III \\
\hline $\begin{array}{l}\text { Solyc09 } \\
\text { g015770 }\end{array}$ & $\begin{array}{l}\text { WRKY transcription factor } \\
\text { (WRKY70, WRKY6) }\end{array}$ & GTTATAAACAATTCTGATGTCGTCG & TCTGATTCTGAAGTTTTCСTTCTC & 131 & II \\
\hline $\begin{array}{l}\text { Solyc11 } \\
\text { g011050 }\end{array}$ & $\begin{array}{l}\text { MYB-related transcription factor } \\
\text { (THM16, ODORANT1) }\end{array}$ & ATGGGGAGACAACCTTGTTGTG & TTCCACATCTCAATAACCCTGCTA & 151 & I \\
\hline $\begin{array}{l}\text { Solyc11 } \\
\text { g069030 }\end{array}$ & $\begin{array}{l}\text { MYB-related transcription factor } \\
\text { (BLIND) }\end{array}$ & CTCCATGTTGTGATAAAGCAAATG & CCACATCTCCTTAGTCCTGCTT & 142 & - \\
\hline $\begin{array}{l}\text { Solyc12 } \\
\mathrm{g} 013620\end{array}$ & $\begin{array}{l}\text { NAC domain-containing protein } \\
\text { (JA2) }\end{array}$ & TATTTATGTAAGAAAGTTGCTGGAC & CCAAATGTCGCCTTACTAGGTA & 107 & II \\
\hline \multicolumn{6}{|c|}{ Table 2. Tomato stress-responsive genes selected from microarray data analysis } \\
\hline Gene locus & Protein product (synonyms) & Oligonucleotide s & equences $\left(5^{\prime}\right.$ to $\left.3^{\prime}\right)$ & $\begin{array}{l}\text { Product } \\
\text { (bp) }\end{array}$ & Cluster \\
\hline $\begin{array}{l}\text { Solyc01 } \\
\text { g079200 }\end{array}$ & $\begin{array}{c}\text { Gibberellin 2- } \beta \text {-dioxigenase } 2 \\
(\text { GA2ox-3) }\end{array}$ & TCAATGGAGATAAAGGTGATCTTG & GTAATCATTTGTCACCGAGCTGAA & 122 & 12 \\
\hline $\begin{array}{l}\text { Solyc01 } \\
\text { g107390 }\end{array}$ & $\begin{array}{c}\text { Auxin and ethylene responsive GH3- } \\
\text { like protein }\end{array}$ & CCGGTCGTAACTTATGAAGATC & CTGACGTTCCAGAGCTAGTG & 118 & 12 \\
\hline $\begin{array}{l}\text { Solyc01 } \\
\text { g107730 }\end{array}$ & D-type cyclin (CYCD3;2) & GACTCAACTTGCTGCTGTCAC & CATATTTTGCATCCTCCACTTGGA & 108 & 8 \\
\hline
\end{tabular}




\begin{tabular}{|c|c|c|c|c|c|}
\hline $\begin{array}{l}\text { Solyc01 } \\
\text { g111660 }\end{array}$ & $\begin{array}{l}\text { Aquaporin/plasma membrane } \\
\text { intrinsic protein } 3\end{array}$ & GACGGAGTTGGTATTCTCGG & TGGGTTAATATGTCCACCAGAG & 99 & 11 \\
\hline $\begin{array}{l}\text { Solyc02 } \\
\text { g064830 }\end{array}$ & Auxin-responsive $\mathrm{GH} 3$ family protein & AGGAAATTCAACCTGATATTCAACG & GCAGATGTCCCCGAGCTGGT & 103 & 12 \\
\hline $\begin{array}{l}\text { Solyc02 } \\
\text { g069490 }\end{array}$ & $\begin{array}{l}\text { FAD linked oxidase domain protein } \\
\text { (DWARF1, DIM) }\end{array}$ & CCACACAAAGTGAGGCTATTAG & CAGCCAAATTGGATATACCTCCA & 134 & 11 \\
\hline $\begin{array}{l}\text { Solyc02 } \\
\text { g084850 }\end{array}$ & $\begin{array}{l}\text { Dehydrin-like protein } \\
\text { (Tas.14/RAB18) }\end{array}$ & GCACTGGTGGAGAATATGGAAC & TCCATCATCCTCCGACGAGC & 110 & 13 \\
\hline $\begin{array}{l}\text { Solyc03 } \\
\text { g006880 }\end{array}$ & Gibberellin 20-oxidase (GA20ox) & CACTCTCTTTTCGTTACTCCG & AATATTCTTGATAAACATTCCCGAG & 114 & 10 \\
\hline $\begin{array}{l}\text { Solyc03 } \\
\text { g095510 }\end{array}$ & Protein kinase 2 (KIN2) & GATTTTGGAGAAAGATCACGCTG & GGTATAGTCTGTATTTGGTCTGGA & 119 & 18 \\
\hline $\begin{array}{l}\text { Solyc03 } \\
\text { g096460 }\end{array}$ & $\begin{array}{l}\text { Lipoxygenase homology domain- } \\
\text { containing protein } 1\end{array}$ & GGAGTAGCAGCTCAAGTTAAC & TGTGTAAACACAATCTTCAGCAG & 99 & 8 \\
\hline $\begin{array}{l}\text { Solyc05 } \\
\text { g007180 }\end{array}$ & $\begin{array}{l}\text { Homeobox-leucine zipper protein } \\
\text { (ATHB13, HAT7, JA1) }\end{array}$ & САAАТTTCATGCTACAААСТССТС & CCCAAAAATGAAGCAATACCATGG & 118 & 9 \\
\hline $\begin{array}{l}\text { Solyc07 } \\
\text { g043130 }\end{array}$ & Root phototropism protein 2 & TGGTGCACTTGTTGTGTTAAAGTC & CGCCTCCACACACGCCTTAG & 112 & 10 \\
\hline $\begin{array}{l}\text { Solyc07 } \\
\text { g049530 }\end{array}$ & $\begin{array}{c}\text { 1-Aminocyclopropane-1-carboxylate } \\
\text { oxidase (ACCox) }\end{array}$ & TTAACTTGGAAAAGCTCAATGGAG & GAATTCCATGGTTCACCAACTCAA & 105 & 22 \\
\hline $\begin{array}{l}\text { Solyc 11 } \\
\mathrm{g} 071620\end{array}$ & Aldehyde oxidase & GTTGCCATCCGTTGATCCTTC & CAAGCTCCACAACСАССТTC & 105 & 1 \\
\hline
\end{tabular}

